\title{
Pulmonary Evaluation of Patients Presenting with Dermatological Manifestations of Sarcoidosis
}

\author{
JAMES S. BOWER, M.D.
}

Sarcoidosis may involve virtually any organ system and its initial manifestations are protean. Dermatologic manifestations of sarcoidosis first cause patients to seek medical attention in approximately $10 \%$ of cases, ${ }^{1}$ and at least $50 \%$ of patients with sarcoidosis who are initially evaluated for dermatologic complaints either have pulmonary disease at the time of presentation or subsequently go on to develop pulmonary sarcoidosis. ${ }^{2}$ Pulmonary disease accounts for a large portion of the morbidity and mortality caused by sarcoidosis. It is important that pulmonary involvement be recognized and treated prior to the development of extensive irreversible lung damage. Since the dermatologist may be the first physician to evaluate a patient with sarcoidosis and may be the patient's primary care physician, it is important that he have a clear understanding of pulmonary sarcoidosis. This review summarizes the manifestations of pulmonary sarcoidosis and provides guidelines for its evaluation and treatment.

\section{Relationship of Pulmonary and Dermatologic Manifestations of Sarcoidosis}

The prevalence of dermatologic abnormalities reported in patients with sarcoidosis has varied from series to series as seen in Table $1 .^{3-8}$ Erythema nodosum has been found in recent series in as few as 3\% and as many as $31 \%$ of cases, and it appears to be much more frequent in Europe than in North America. Other skin manifestations including plaques, maculopapular eruptions, subcutaneous nodules, and lupus pernio occur in 13\% to $39 \%$ of patients. More than $90 \%$ of patients with erythema nodosum and approximately $70 \%$ of patients with other skin manifestations also have pulmonary sarcoidosis. $^{7}$

Address for reprints: James S. Bower, M.D., Assistant Professor of Internal Medicine, Pulmonary Division, University of Michigan Hospital, 1405 E. Ann Street, Ann Arbor, MI 48109.
From the Pulmonary Division, Department of Internal Medicine, University of Michigan Medical Center, Ann Arbor, Michigan

The dermatologic and pulmonary manifestations of sarcoidosis generally follow a parallel course. Patients who present with bilateral hilar adenopathy and erythema nodosum virtually always experience clearing of both the skin and intrathoracic disease in six months to one year. Patients with other dermatologic manifestations, however, tend to have a chronic indolent course with gradually progressing lung damage. Only $20 \%$ of patients with skin lesions other than erythema nodosum experience complete clearing of their chest roentgenogram and clearing rarely occurs in the presence of lupus pernio. ${ }^{8}$

\section{Symptoms and Signs of Pulmonary Sarcoidosis}

Pulmonary sarcoidosis is frequently asymptomatic and may be brought to attention because of an abnormal

TABlE 1. Prevalence of Dermatologic Manifestations of Sarcoidosis

\begin{tabular}{llcc}
\hline \multicolumn{1}{c}{ Author } & $\begin{array}{c}\text { Country/Number } \\
\text { of Patients }\end{array}$ & $\begin{array}{c}\text { Erythema } \\
\text { Nodosum }\end{array}$ & $\begin{array}{c}\text { Other Skin } \\
\text { Lesions }\end{array}$ \\
\hline $\begin{array}{c}\text { Stones and Israel } \\
\text { (1960) } \\
\text { Lofgren and Stavenow } \\
(1961)\end{array}$ & USA/211 & $3 \%$ & $26 \%$ \\
$\begin{array}{c}\text { Mayock } \\
(1963)\end{array}$ & USA $/ 145$ & $25 \%$ & $32 \%$ \\
$\begin{array}{c}\text { Bower } \\
(1963)\end{array}$ & USA $/ 69$ & $3 \%$ & $39 \%$ \\
$\begin{array}{l}\text { James and Sharma } \\
(1967)\end{array}$ & England/537 & $31 \%$ & $25 \%$ \\
Sharma $^{8}$ & USA $/ 145$ & $10 \%$ & $18 \%$ \\
\hline
\end{tabular}




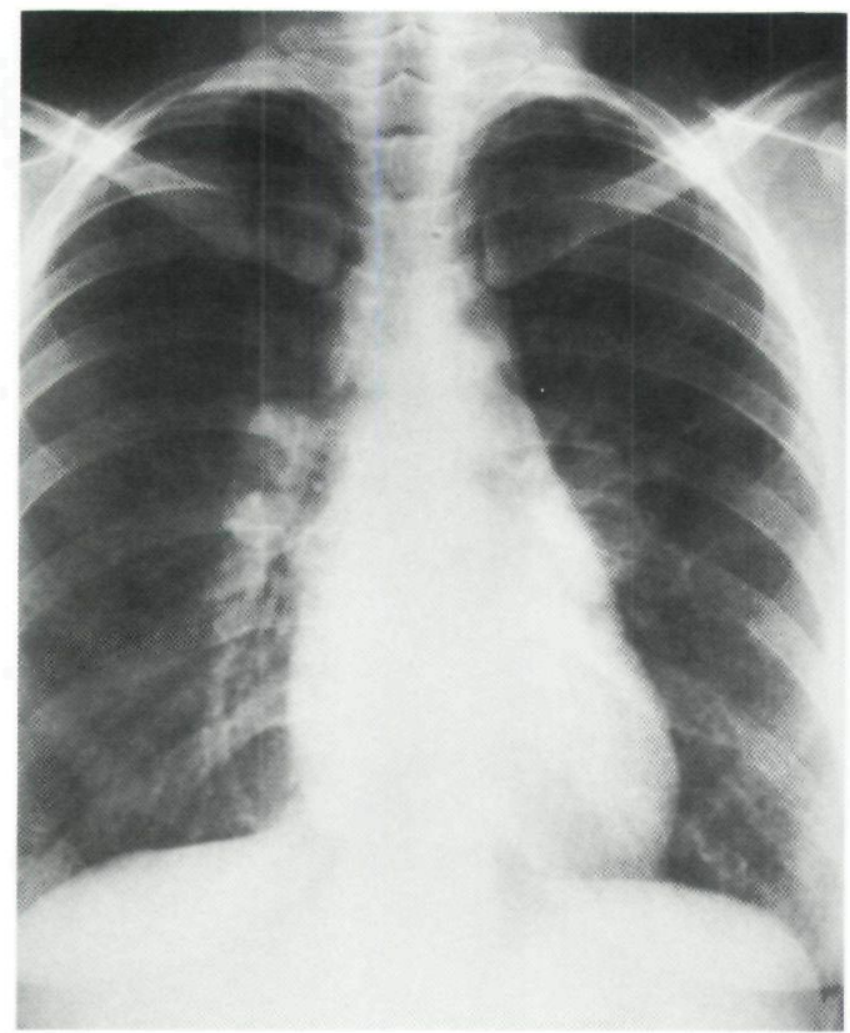

FiG. 1. (A) Chest roentgenogram typical of stage I sarcoidosis showing bilaterial hilar adenopathy with clear lung fields. (B) Chest roentgenogram typical of stage II sarcoidosis showing both hilar adenopathy and bilateral pulmonary infiltrates. (C) Chest roentgenogram typical of stage III sarcoidosis showing bilateral pulmonary infiltrates without hilar adenopathy.

routine chest roentgenogram. When symptoms occur they include dyspnea, cough, chest pain, and hemoptysis. Approximately $35 \%$ of patients with sarcoidosis experience dyspnea at some time in the course of their disease, $35 \%$ experience cough, 15 to $20 \%$ complain of chest pain, and less than $5 \%$ experience hemoptysis. Hoarseness occurs in approximately $2 \%$ of patients and is a manifestation of laryngeal involvement. Rarely laryngeal sarcoidosis may lead to stridor and high grade upper airway obstruction.

Examination of the lungs is also frequently normal in patients with sarcoidosis even in the presence of advanced parenchymal lung disease. Bower studied 69 patients with intrathoracic sarcoidosis and found only 17 $(25 \%)$ in whom rales, rhonchi, or wheezes could be detected. ${ }^{6}$ The reason for this paucity of physical findings is unknown, but significant pulmonary disease is frequently present despite a normal lung examination.
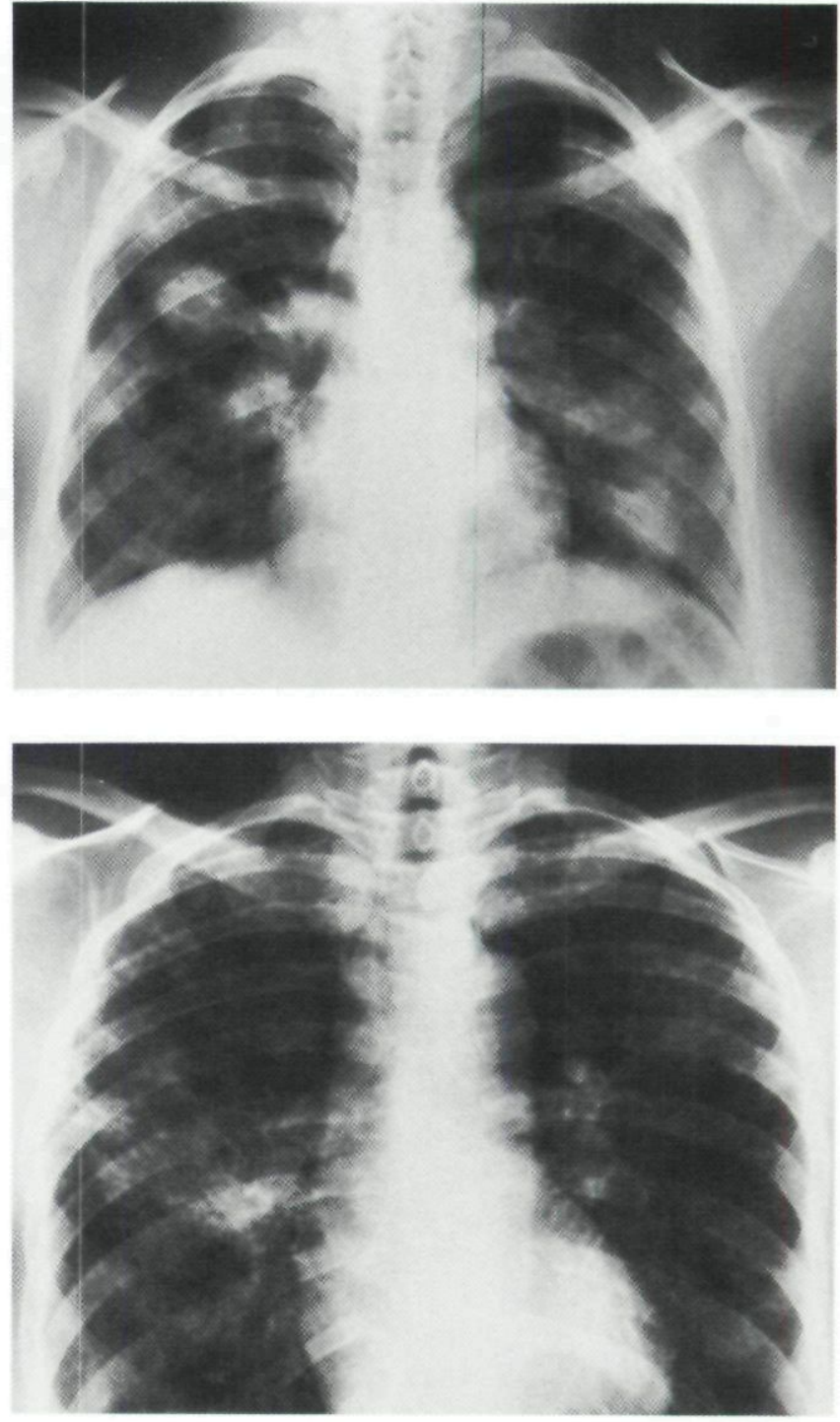

\section{Chest Roentgenogram in Sarcoidosis}

Since symptoms and physical findings are not sensitive indicators of the presence of pulmonary sarcoidosis, the chest roentgenogram is an extremely important part of the pulmonary evaluation. It can be expected to be abnormal in slightly more than $90 \%$ of patients with sarcoidosis. Abnormal findings consist of some combination of intrathoracic adenopathy and pulmonary parenchymal infiltrates and can be classified according to the stage of involvement (Fig. 1). ${ }^{9}$

Roentgenographic stage I disease is characterized by the presence of bilateral hilar adenopathy without pulmonary parenchymal infiltrates. Patients with stage I disease are usually asymptomatic, though as many as $10 \%$ may experience a significant feeling of breathlessness. Spontaneous resolution of sarcoidosis occurs in $85 \%$ of patients with stage I disease. Stage II disease is 
characterized by the presence of both hilar adenopathy and pulmonary parenchymal infiltrates. Patients in this stage are more frequently symptomatic than stage I patients and have a slightly worse prognosis. Approximately $60 \%$ experience spontaneous clearing of their chest roentgenogram while the remainder have chronic persistent disease. Patients with stage III disease have parenchymal infiltrates without hilar adenopathy. They have the most symptoms, the greatest functional impairment, and the worst prognosis. Only $20 \%$ of these patients ever experience clearing of their chest roentgenogram and many have significant pulmonary disability.

It should also be recognized that significant pulmonary parenchymal sarcoidosis may be present even in the presence of a completely normal chest roentgenogram. This pulmonary involvement can be demonstrated either by pulmonary function testing or by lung biopsy. Epler and colleagues, for instance, reported 62 patients with biopsy confirmed pulmonary sarcoidosis among whom $5 \%$ had completely normal chest roentgenograms. ${ }^{10}$ Pleural effusions are uncommon in patients with sarcoidosis and occur in $1 \%$ to $2 \%$ of cases. ${ }^{11}$ The fluid is exudative and may be either unilateral or bilateral. Calcification of hilar nodes and pulmonary parenchyma may occur in patients with longstanding disease.

\section{Pulmonary Function Tests in Sarcoidosis}

Abnormalities of pulmonary function tests in patients with sarcoidosis are not well correlated with abnormalities on chest roentgenogram. ${ }^{12}$ Substantial abnormalities are often present in patients without roentgenographic evidence of parenchymal lung disease. Conversely, patients with diffuse parenchymal infiltrates may have little in the way of functional impairment. The reason for this poor correlation is not known but may be related to the relative proportion of granulomas present in the interstitium, the pulmonary vessels, and the airways.

Pulmonary function abnormalities that occur in patients with sarcoidosis include decrements in total lung capacity, decreases in expiratory flow rates, and impairment of gas exchange. These alterations may exist independently or may be found together. Their severity is variable and they may cause no symptoms or may result in significant exercise limitation.

One of the most common abnormalities found on routine pulmonary function tests in patients with sarcoidosis is a decreased diffusing capacity for carbon monoxide $\left(\mathrm{D}_{L} \mathrm{CO}\right)$. The $\mathrm{D}_{L} \mathrm{CO}$ is frequently diminished even in stage I disease. ${ }^{13}$ Measured decreases are believed to occur predominantly because of compromise of the pulmonary capillary bed by granulomatous in-

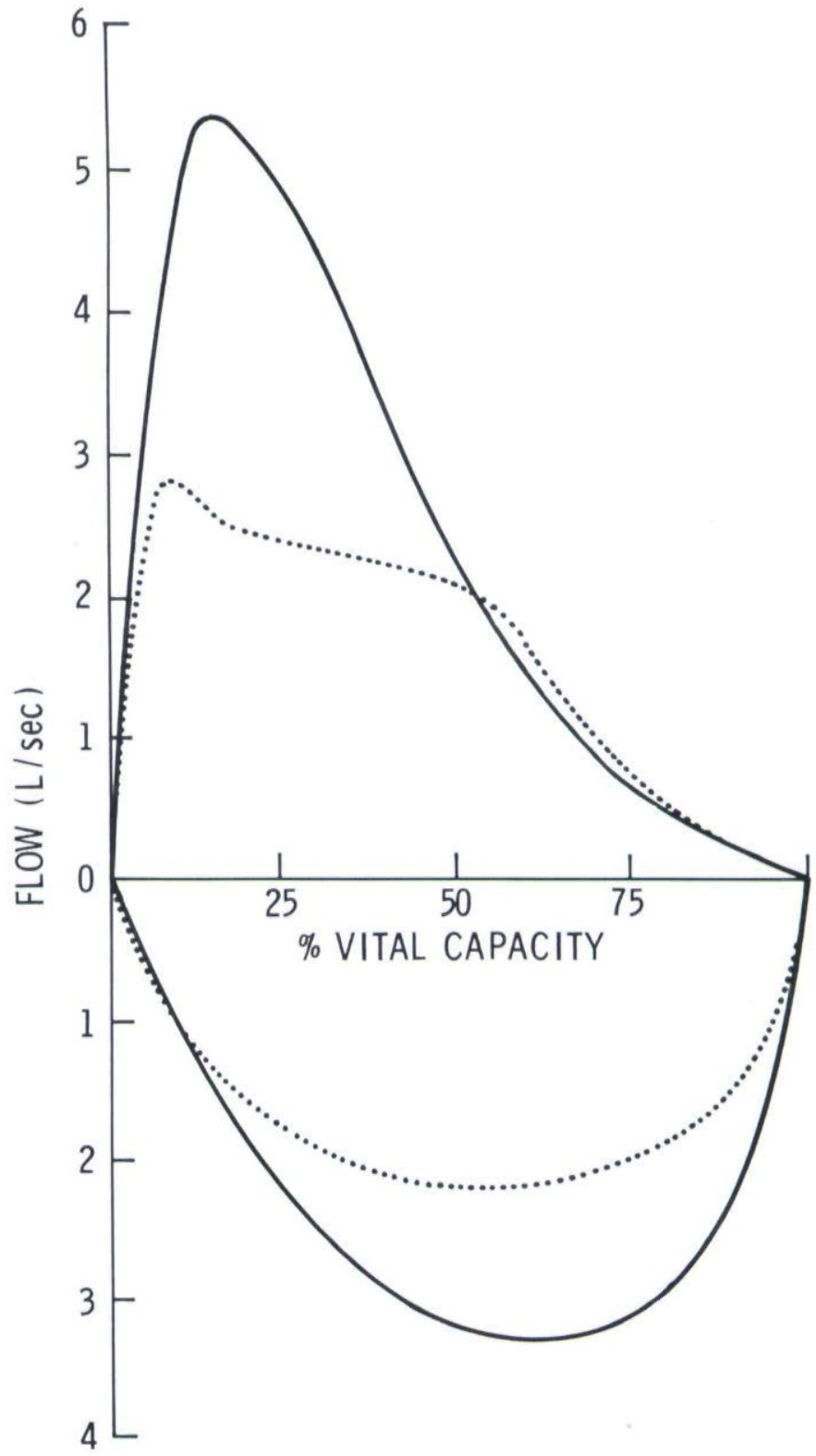

FIG. 2. The continuous line represents a normal maximal flowvolume curve in a patient with sarcoidosis. The dotted line depicts the maximal flow-volume curve of the same patient after the development of upper airway obstruction due to laryngeal sarcoidosis. Total lung capacity is at $0 \%$ of the vital capacity and residual volume is at $100 \%$ Expiratory flow rates are shown above the abscissa and inspiratory flow rates are shown below. Expiratory flow rates are decreased during the first half of the forced vital capacity maneuver while inspiratory flow rates are more symmetrically decreased.

flammation with a resulting decrease in the area of the lung's diffusing surface.

Reductions in total lung capacity are found in more advanced disease. It is believed to result from granulomatous inflammation in the lung interstitium, which decreases the compliance of the lungs and eventually causes obliteration of alveolar air spaces. Both of 
TABLE 2. Evaluation of Pulmonary Sarcoidosis

1. All patients:

a. History of respiratory symptoms;

b. Physical examination of the lungs;

c. Chest roentgenogram; and

d. Pulmonary function tests:

(1) Spirometry including a maximal flow volume curve;

(2) Total lung capacity; and

(3) Diffusing capacity for carbon monoxide

2. Selected patients:

a Arterial blood gas tension at rest and during exercise; and

b. Fiberoptic bronchoscopy with biopsy.

these consequences of interstitial granulomas serve to decrease the volume of gas that the patient can inspire and hence decrease total lung capacity.

Obstructive airways disease is also a feature of pulmonary sarcoidosis and is characterized by decreased expiratory air flow rates. It may be mild and only detected by sensitive physiologic tests or may be quite severe and result in a substantial alteration in the patient's exercise tolerance. The etiology of this obstructive airway disease may be related to small airway compromise by granulomas or to distortion of larger airways resulting from pulmonary fibrosis. In addition, we have recently collected data in our laboratory which suggests that airway granulomas cause increased airways smooth muscle constriction in response to nonspecific airway irritants. ${ }^{14}$

Upper airway obstruction may also occur in patients with sarcoidosis and is usually due to laryngeal involvement. ${ }^{15}$ Obstruction of the large airways can be differentiated from more peripheral airways obstruction by plotting air flow against the volume of gas expired during a forced expiratory maneuver. Peripheral airways obstruction causes decreased flow rates in the last half of the vital capacity, while obstruction of large central airways produces decreased flow rates during the first half of the forced vital capacity maneuver. The characteristic alteration in the flow volume curve seen in upper airway obstruction is depicted in Fig. 2. It is of some importance that upper airway obstruction be detected since laryngeal sarcoidosis may cause complete upper airway obstruction and asphyxiation.

\section{Arterial Blood Gas Determination in Sarcoidosis}

The partial pressures of oxygen $\left(\mathrm{PO}_{2}\right)$ and carbon dioxide $\left(\mathrm{PCO}_{2}\right)$ in the arterial blood of patients with early sarcoidosis are often normal. As the pulmonary parenchymal disease progresses, the $\mathrm{PO}_{2}$ falls. Advanced parenchymal disease particularly in the presence of fibrotic changes may result in significant hypoxemia $\left(\mathrm{PO}_{2}\right.$ $<60 \mathrm{mmHg}$ ) and occasionally in hypercarbia $\left(\mathrm{PCO}_{2}>\right.$
$44 \mathrm{mmHg}$ ). Although moderate exercise usually results in little change in arterial blood gases, it may cause the $\mathrm{PO}_{2}$ to fall in patients with advanced pulmonary sarcoidosis. Measurement of arterial blood gas tensions in patients with advanced disease may be useful in determining the need for treatment with supplemental oxygen.

\section{Diagnosis of Sarcoidosis}

Confident diagnosis of sarcoidosis requires: (1) a clinical and roentgenographic presentation consistent with sarcoidosis; (2) biopsy demonstration of noncaseating granulomas; and (3) exclusion by special stains and cultures of specific infections causing granulomatous inflammation. Biopsy material can be obtained from any organ but is most frequently obtained from skin, lung, or lymph nodes. Since local "sarcoid reactions" have been reported in neoplastic diseases, it is occasionally desirable to obtain tissue from more than one source.

The recent development of fiberoptic bronchoscopy with transbronchial lung biopsy has made lung tissue relatively easy to obtain. One can expect to find noncaseating granulomas via transbronchoscopic biopsy in $66 \%$ of patients with stage I disease, $84 \%$ of patients with stage II disease, and $83 \%$ of patients with stage III disease. ${ }^{16}$ Endobronchial biopsies also reveal granulomas particularly when mucosal abnormalities are visualized. ${ }^{17}$

The Kveim test may also be used as an aid to diagnosis. A positive Kveim test occurs in 70 to $90 \%$ of patients with active disease and is associated with a low rate ( 1 to $2 \%$ ) of false positive results. ${ }^{18}$ It is rarely helpful, however, in patients with diffuse pulmonary infiltrates without hilar adenopathy, and standardized Kveim antigen is not readily available.

\section{Evaluation and Treatment of Pulmonary Sarcoidosis}

Patients presenting with dermatologic manifestations of sarcoidosis should have an initial pulmonary evaluation as outlined in Table 2. All patients should be questioned concerning symptoms of dyspnea, cough, chest pain, or hemoptysis and should undergo careful physical examination of the lungs. In addition, all patients should have a chest roentgenogram and pulmonary function studies including spirometry, determination of total lung capacity, and measurement of the diffusing capacity for carbon monoxide. In selected patients in whom the diagnosis of sarcoidosis is in question, the performance of fiberoptic bronchoscopy with transbronchial lung biopsy provides a source of tissue for examination. When serious impairment of pulmonary function exists and administration of supplemental oxygen is being 
considered, arterial blood gases at rest and following exercise should be obtained.

Pulmonary sarcoidosis is best treated with systemic corticosteroids. In the majority of cases this results in both symptomatic and physiologic improvement. Although the effect of corticosteroids on long-term prognosis has not been clearly established, it is likely that it results in preservation of lung function. Not all patients with pulmonary sarcoidosis, however, should be treated. Treatment should be reserved for patients with dyspnea on exertion and significantly abnormal or deteriorating pulmonary function tests and patients with persistent parenchymal infiltrates not resolving over a six-month period. ${ }^{19}$ Baseline pulmonary function tests and an initial chest roentgenogram are thus essential for making initial decisions concerning steroid therapy and are useful as a reference for later comparison.

Treatment of pulmonary sarcoidosis is started with oral prednisone in a dose of $40 \mathrm{mg}$ per day. This should be continued for four weeks, and the patient's symptoms, chest roentgenogram, and pulmonary function studies should be evaluated again. If no improvement has occurred, the prednisone is gradually discontinued over the next two to three weeks. If improvement has occurred, the dose of prednisone is decreased to 20 to $40 \mathrm{mg}$ every other day. This amount is continued at least one year prior to attempting to completely withdraw steroid therapy.

\section{Summary}

Patients presenting with dermatologic manifestations of sarcoidosis frequently have coexisting lung disease and should have pulmonary evaluation including a history of pulmonary symptoms, an examination of the lungs, a chest roentgenogram, and pulmonary function studies. In selected cases, fiberoptic bronchoscopy and the determination of arterial blood gas tensions may also prove useful. The data obtained from this evaluation aids in the decisions concerning the institution of cortico- steroid treatment for pulmonary sarcoidosis and provides baseline information for following the course of the disease.

\section{References}

1. Israel HL, Atkinson GW: Sarcoidosis. Basics RD 114(1):1, 1978

2. Hanno R, Needelman A, Eiferman RA, Callen JP: Cutaneous sarcoidal granulomas and the development of systemic sarcoidosis. Arch Dermatol (in press)

3. Sones M, Israel HL: Course and prognosis of sarcoidosis. Am J Med 29:84, 1960

4. Löfgren S, Stavenow S: Course and prognosis of sarcoidosis. Am Rev Resp Dis 84(5):71, 1961

5. Mayock R., Bertrand PL, Morrison CE, et al: Manifestations of sarcoidosis: analysis of 145 patients with a review of nine series selected from the literature. Am J Med 35:67, 1963

6. Bower G: Intrathoracic sarcoidosis: a review of 69 cases. Chest 44:457, 1963

7. James DG: Sarcoidosis. In: Dermatology In General Medicine. Edited by Fitzpatrick TB. New York, McGraw Hill, 1971, p 1549

8. Sharma OP: Cutaneous sarcoidosis: clinical features and management. Chest 61:320, 1972

9. Sharma OP: Sarcoidosis: A clinical approach. Springfield, Charles C Thomas, 1975, pp 30-64

10. Epler GR, McCloud TC, Gaensler EA, et al: Normal chest roentgenogram in chronic diffuse infiltrative lung disease. $\mathrm{N}$ Engl J Med 298:935, 1978

11. Beckman JF, Zimmet SM, Chun BK, et al: Spectrum of pleural involvement in sarcoidosis. Arch Intern Med 136:323, 1976

12. Bates DV, Macklem PT, Christie RV: Pulmonary sarcoidosis. In: Respiratory Function in Disease. Philadelphia, WB Saunders, 1971, pp 287-298

13. Sharma OP, Colp C, Williams $M H$ : Pulmonary function studies in patients with bilateral sarcoidosis of hilar lymph glands. Arch Intern Med 117:436, 1966

14. Bechtel J, Starr T, Dantzker DR, et al: Airways hyperreactivity in sarcoidosis. Am Rev Resp Dis 121:110, 1980

15. Bower JS, Belen J, Weg JG, et al: Manifestations and treatment of laryngeal sarcoidosis. Am Rev Resp Dis 122:325, 1980

16. Roethe R, Fuller PB, Byrd RB, et al: Transbronchoscopic lung biopsy in sarcoidosis: optimal number and sites for diagnosis. Chest 77:400, 1980

17. Friedman $\mathrm{OH}$, Blaumgrund SM, Siltzbach LE: Biopsy of the bronchial wall as an aid in diagnosis of sarcoidosis. JAMA 183:120, 1963

18. James DG, Sharma OP: The Kveim Test: report of a new British antigen. Lancet ii:1274, 1967

19. DeRemee RA: The present status of treatment of pulmonary sarcoidosis: a house divided. Chest 71:388, 1977

\section{Mycosis Fungoides}

Mycosis fungoides is generally regarded as a malignant T-cell lymphoma arising in skin. ${ }^{1}$ Its cutaneous manifestations range from pruritic erythematous macules through infiltrated scaly plaques to tumours which may ulcerate and become infected. In advanced disease the lymph-nodes, liver, and spleen may become involved, and the outcome is then usually fatal. It is generally accepted that advanced mycosis fungoides is resistant to treatment, but there is disagreement about the management of the disease in its early stages when it is confined to the skin. Early and aggressive therapy with curative intent is advocated by some, but many centres favour a conservative and essentially symptomatic approach to treatment. Photochemotherapy (PUVA) has been reported to be of benefit in the treatment of mycosis fungoides. ${ }^{2-8}$ The mode of action is thought to be related to inhibition of DNA synthesis and mitosis in the T lymphocytes in the cutaneous infiltrate.-Briffa DV, Warin AP, Harrington, $\mathrm{Cl}$, et al: Photochemotherapy in mycosis fungoides. Lancet i:49, 1980 
This document is a scanned copy of a printed document. No warranty is given about the accuracy of the copy. Users should refer to the original published version of the material. 